Fayetteville State University

DigitalCommons@Fayetteville State University

Math and Computer Science Faculty Working

Papers

Math and Computer Science

Fall 2011

\title{
Computer Simulation of a Mathematical Model of HAART Therapy for HIV-1 AIDS
}

Frank Nani

Fayetteville State University, fnani@uncfsu.edu

Mingxian Jin

Fayetteville State University, mjin@uncfsu.edu

Follow this and additional works at: https://digitalcommons.uncfsu.edu/macsc_wp

\section{Recommended Citation}

Nani, Frank and Jin, Mingxian, "Computer Simulation of a Mathematical Model of HAART Therapy for HIV-1 AIDS" (2011). Math and Computer Science Faculty Working Papers. 19.

https://digitalcommons.uncfsu.edu/macsc_wp/19

This Conference Proceeding is brought to you for free and open access by the Math and Computer Science at DigitalCommons@Fayetteville State University. It has been accepted for inclusion in Math and Computer Science Faculty Working Papers by an authorized administrator of DigitalCommons@Fayetteville State University. For more information, please contact dballar5@uncfsu.edu. 


\title{
Computer Simulation of a Mathematical Model of HAART Therapy for HIV-1 AIDS
}

\author{
Frank Nani and Mingxian Jin \\ Department of Mathematics and Computer Science \\ Fayetteville State University \\ Fayetteville, NC 28301, USA
}

\begin{abstract}
A clinically plausible mathematical model is constructed to describe the patho-physiological dynamics of HIV- 1 induced AIDS during HAART therapy. The model equations incorporate physiological interactions between non-infected helper $\mathbf{T}$ cells, HIV- 1 infected helper $T$ cells, HIV-1 virions in the blood plasma, HIV-1 specific cytotoxic T cells and drug molecules of the HAART protocol. Investigative computer simulations are performed to elucidate some therapeutic scenarios such as viral annihilation and efficacious HAART therapy. In particular, some mathematical criteria are derived for therapeutic outcomes such as viral persistence and viral annihilation.
\end{abstract}

Keywords: HAART therapy, computer simulations, mathematical modeling, HIV-1 dynamics, AIDS cure criteria

\section{INTRODUCTION}

In a previous publication [11], we presented a mathematical model describing the patho-physiological dynamics of the HIV-1 virions during the asymptomatic latency phase. As the HIV-1 virions increase in the blood plasma, the number density of the $\mathrm{CD}^{+}$helper $\mathrm{T}$ cells decrease and the patient eventually develops AIDS. Currently, the most efficacious method for inducing a decline in number of HIV-1 virions and effecting immune system reconstitution, is by using highly active antiretroviral therapy (HAART) [10, 15]. A typical HAART treatment protocol consists of combinations of protease inhibitors (PIs), and types of reverse transcriptase inhibitors (RTIs), which are fabricated as a compact matrix tablet $[1,2,10]$. It is clinically observed that the HAART treatment regimen has associated side effects such as gastro-intestinal toxicity, lipodystrophy, anemia, thrombocytopenia, and renal failure $[3,9,10]$.

Several mathematical models have been developed to describe therapy of HIV-1 induced AIDS [4, 5, 12, 13]. The authors Kirschner and Webb $[4,5]$ constructed models that described viral dynamics and drug resistance during monotherapy of HIV-1 infection. Perelson et al.[12] described the decay characteristics of HIV-1 infected compartments during combination therapy. In [15], Ye, Kourtis and Kirschner constructed an elaborate mathematical model which described the reconstitution of thymic function in HIV-1 patients during HAART therapy. Recent models, which involve optimal control therapies of HAART, include those by Stengel [14], Joshi [8], Adams et al. [1], Caetano and Yoneyama [2], and Joly [7].
In this paper, an elaborate clinically plausible mathematical model is constructed to describe HAART therapy of HIV-1 induced AIDS. This model incorporates constant continuous and periodic transdermal delivery, Michaelis-Menten drug absorption and clearance kinetics, and effects of viral latent reservoirs. Mathematical analyses of the model persistence are performed and viral persistence criteria are calculated. Investigative computer simulations are performed using hypothetical AIDS patients' physiological parameters.

The major contribution of the current research is the formulation of robust criteria under which the HIV-1 virions will persist or be annihilated during the HAART drug therapy.

\section{PARAMETERS}

The model parameters, constants, and variables are listed as follows.

$x_{1}$ : the number density of non-HIV-1-infected $\mathrm{CD} 4^{+}$helper T-lymphocytes per unit volume

$x_{2}$ : the number density of HIV-1 infected $\mathrm{CD}^{+}$helper T-lymphocytes per unit volume

$x_{3}$ : the number density of HIV-1 virions in the blood plasma per unit volume

$x_{4}$ : the number density of HIV-1 specific $\mathrm{CD}^{+}$cytotoxic T-lymphocytes per unit volume

$x_{5}$ : the concentration of drug molecules of the HAART treatment protocol

$S_{1}$ : rate of supply of un-infected $\mathrm{CD}^{+} \mathrm{T}_{4}$-lymphocytes

$S_{2}$ : rate of supply of latently infected $\mathrm{CD}^{+} \mathrm{T}_{4}$-lymphocytes

$S_{3}$ : rate of supply of HIV-1 virions from macrophage, monocytes, microglial cells and other lymphoid tissue different from $\mathrm{T}_{4}$-lymphocytes

$S_{4}$ : rate of supply of $\mathrm{CD}^{+} \mathrm{T}_{8}$-lymphocytes from the thymus

$D$ : rate of HAART drug infusion by transdermal delivery

$a_{i}, b_{i}$ : constant associated with activation of lymphocytes by cytokine interleukin-2 (IL-2) $(i=1,2,3,4)$

$c$ : rate of HAART drug degradation and excretion

$\alpha_{i}$ : constant associated with HIV-1 infection of $\mathrm{CD}^{+} \mathrm{T}_{4}$ helper cells $(i=1,2,3)$

$\beta_{1}$ the number of HIV-1 virions produced per day by replication and budding in $\mathrm{CD}^{+} \mathrm{T}_{4}$ helper cells 
$\beta_{2}$ : rate constant associated with replication and "budding" of HIV-1 in syncytia CD4 ${ }^{+} \mathrm{T}_{4}$ helper cells per day per microliter $(\mu l)$ and released into the blood plasma

$\beta_{3}$ : the number of HIV-I virions produced per day by replication and "budding" in non-syncytia $\mathrm{CD}^{+} \mathrm{T}_{4}$ helper cells and released into the blood plasma

$\eta_{i}$ : constant depicting the rate of which HIV-1 virions incapacitate the $\mathrm{CD}^{+} \mathrm{T}_{8}$ cytotoxic cells $(i=1,2)$

$\left(\sigma_{0}, \lambda_{0}\right)$ :Michaelis-Menten metabolic rate constants associated with HAART drug elimination

$\left(\sigma_{i}, \lambda_{i}\right)$ :Michaelis-Menten metabolic rate constants associated with HAART drug pharmacokinetics $(i=2,3)$

$\xi_{i}$ : cytotoxic coefficient where $0 \leq \xi_{i} \leq 1(i=2,3)$

$q_{i}$ : constant depicting competition between infected and un-infected $\mathrm{CD}^{+} \mathrm{T}_{4}$ helper cells $(i=1,2)$

$k_{i}$ : constant depicting degradation, loss of clonogenicity or "death" ( $i=1,2,3,4)$

$e_{i 0}$ : constant depicting death or degradation or removal by apoptosis (programmed cell death) $(i=1,2,3,4)$

$K_{i}$ : constant associated with the killing rate of infected $\mathrm{CD}_{4}^{+}$ $\mathrm{T}_{4}$ cells by $\mathrm{CD}^{+} \mathrm{T}_{8}$ cytotoxic lymphocytes $(i=1,2)$

All the parameters are positive.

\section{MODEL EQUATIONS AND ANALYSES}

The HIV-1 patho-physiological dynamics during HAART therapy can be modeled using the following system of non-linear ordinary differential equations:

$\dot{x}_{1}=S_{1}+a_{1} x_{1}^{2} e^{-b_{1} x_{1}}-\alpha_{1} x_{1} x_{3}-q_{1} x_{1} x_{2}-k_{1} x_{1}-e_{10}$

$\dot{x}_{2}=S_{2}+a_{2} x_{1} x_{2} e^{-b_{2} x_{1}}+\alpha_{2} x_{1} x_{3}-q_{2} x_{1} x_{2}-k_{2} x_{2}-\beta_{1} x_{3}$

$-K_{1} x_{2} x_{4}-e_{20}-\frac{\xi_{2} \sigma_{2} x_{2} x_{5}}{\lambda_{2}+x_{5}}$

$\dot{x}_{3}=S_{3}+\beta_{2} x_{2} x_{3}+\beta_{3} x_{3}-\alpha_{3} x_{1} x_{3}-\eta_{1} x_{3} x_{4}-k_{3} x_{3}-e_{30}$

$-\frac{\xi_{3} \sigma_{3} x_{3} x_{5}}{\lambda_{3}+x_{5}}$

$\dot{x}_{4}=S_{4}+a_{4} x_{1} x_{4} e^{-b_{4} x_{1}}-K_{2} x_{2} x_{4}-\eta_{2} x_{3} x_{4}-k_{4} x_{4}-e_{40}$

$\dot{x}_{5}=D f(t)-\frac{\sigma_{0} x_{5}}{\lambda_{0}+x_{5}}-\frac{\sigma_{2} x_{2} x_{5}}{\lambda_{2}+x_{5}}-\frac{\sigma_{3} x_{3} x_{5}}{\lambda_{3}+x_{5}}$

$f(t)=\left\{\begin{array}{c}1 \text { for constant continuous transdermal delivery } \\ |\sin n t| \text { for periodic transdermal delivery }\end{array}\right.$

$x_{i}\left(t_{0}\right)=x_{i 0} \quad$ for $\quad i=\{1,2,3,4,5\}$

The model includes the following clinical improvement:

(i) The drug delivery uses transdermal, stealth-liposome encapsulated drug delivery, instead of the matrix tablet form because of improved therapeutic efficacy and reduced gastro-intestinal toxicity [6]. It is also assumed that elastic liposomes are formulated and selectively targeted such as to reduce toxicity to non-HIV-1-infected CD $4^{+} \mathrm{T}$ cells $\left(x_{1}\right)$ and CD $8^{+}$cytotoxic T cells $\left(x_{4}\right)$.

(ii) The HAART drug is such that each renal excretion and body clearance rate follows Michaelis-Menten kinetics.

(iii) $g\left(x_{1}, x_{j}\right)=a, x_{1} x_{j} e^{-b, x_{1}}$ for $j=(1,2,4)$

This function depicts the process of lymphocyte activation which is mediated by $x_{1}\left(\mathrm{CD} 4^{+}\right)$helper $\mathrm{T}$ cells. These cells secrete a lymphokine called interleukin- 2 .

\section{A. Invariance of Non-Negativity of Solutions}

In this subsection, conditions will be derived under which solutions curves to the model initial values problem for HAART AIDS therapy will remain non-negative and bounded for all $t \in \Re_{+}$.

Let $t_{0}$ be the time at which the HAART therapy begins.

Set

$$
\begin{aligned}
& C_{j}=\sup _{t \in\left[t_{0}, T\right]}\left\lfloor a_{j} x_{1} x_{j} e^{-b_{j} x_{1}}\right\rfloor \text { for } j=\{1,2,4\} \\
& C_{3}=\sup _{t \in\left[t_{0}, T\right]}\left[\beta_{2} x_{2} x_{3}+\beta_{3} x_{3}\right]
\end{aligned}
$$

here $T$ is the time at which the HAART is discontinued.

Also set

$$
\delta_{i}=\sup _{t \in\left\{t_{0}, T\right]}\left[\frac{1}{\lambda_{i}+x_{5}}\right] \text { for } i=\{0,2,3\}
$$

The system of non-linear model equations exhibited in (3.1) can be converted to the following system of differential inequalities using (3.2) and (3.3). Let $f(t)=1$.

$$
\left\{\begin{array}{l}
\dot{x}_{1} \leq S_{1}+C_{1}-k_{1} x_{1}-e_{10} \\
\dot{x}_{2} \leq S_{2}+C_{2}-k_{2} x_{2}-e_{20} \\
\dot{x}_{3} \leq S_{3}+C_{3}-k_{3} x_{3}-e_{30} \\
\dot{x}_{4} \leq S_{4}+C_{4}-k_{4} x_{4}-e_{40} \\
\dot{x}_{5} \leq D-\delta x_{5} \\
\text { where } \delta=\delta_{0}+\delta_{2}+\delta_{3} \\
x_{i}\left(t_{0}\right)=x_{10} \text { where } i=\{1,2,3,4,5\}
\end{array}\right.
$$

The Kamke comparison technique [11] can be used to obtain the following system of non-linear inequalities.

$$
\left\{\begin{array}{c}
x_{1} \leq \frac{S_{i}+C_{1}-e_{i 0}}{k_{i}}+\gamma_{i} e^{-k_{1} t} \quad \text { for } i=\{1,2,34\} \\
x_{5} \leq \frac{D}{\delta}+\gamma_{5} e^{-\delta 1} \quad \text { where } \delta=\delta_{0}+\delta_{2}+\delta_{3} \\
\text { and } \gamma_{1} \in R_{+}=(0, \infty) \text { and } i=\{1,2,3,4,5\}
\end{array}\right.
$$


The preceding analyses lead to the following conclusions.

C1. The solutions to the HAART model are ultimately bounded.

C2. The system is dissipative as implied by the inequalities

$$
\begin{aligned}
& \lim \sup x_{t}(t) \leq \frac{S_{i}+C_{1}-e_{i 0}}{k_{t}}, \quad i=\{1,2,3,4\} \\
& \lim \sup x_{5}(t) \leq \frac{D}{\delta}
\end{aligned}
$$

C3.

$\sup _{t \in\left[t_{0}, T\right]} x_{i}(t)=\max _{t \in\left[t_{L}, t_{p}\right]}\left\{x_{i 0}, \frac{S_{i}+C_{i}-e_{i 0}}{k_{i}}\right\}, \quad i=\{1,2,3,4\}$

$\sup _{t \in\left[t_{0}, T\right]} x_{5}(t)=\max _{t \in\left[t_{0}, T\right]}\left\{x_{50}, \frac{D}{\delta}\right\}$

Therefore, we have the following theorem.

Theorem 1 There exists a $T_{0}>0$ such that for $T_{0}<\mathrm{t}<\infty$, all solutions to the HAART model equations (3.1) with initial values $x_{i 0} \in \Re^{5}=\left\{x_{i} \in \Re \mid x_{i} \geq 0, i=(1,2,3,4,5)\right\}$ will eventually enter the positive invariant region.

$$
\begin{aligned}
A= & \left\{\left(x_{1}, x_{2}, x_{3}, x_{4}, x_{5}\right) \in \Re_{+}^{5} \mid 0 \leq x_{i}<B_{i}\right\} \\
& \text { where } B_{i}=\sup _{i \in\left[t_{0}, T\right]} x_{i}
\end{aligned}
$$

In particular, the solutions are trapped in the region $A$ for all $t \in \Re_{+}$.

\section{B. Persistence of AIDS during HAART}

In this subsection, criteria will be derived under which the HIV-1 virions will persist under HAART therapeutic protocols, with constant continuous infusion with rate $D$.

$$
\begin{aligned}
& m_{i}=\inf _{t \in\left[t_{0}, T\right]}\left\{a_{i} x_{1} x_{i} e^{-b_{i} x_{1}}\right\} \text { where } i=\{1,2,4\} \\
& L_{1}=\sup _{t \in\left[t_{0}, T\right]}\left\{\alpha_{1} x_{3}+q_{1} x_{2}+k_{1}\right\} \\
& L_{2}=\sup _{t \in\left[t_{0}, T\right]}\left\{q_{2} x_{1}+k_{2}+K_{1} x_{4}+\frac{\xi_{2} \sigma_{2} x_{2} x_{5}}{\lambda_{2}+x_{5}}\right\} \\
& U_{1}=\sup _{r \in\left[t_{0}, T\right]}\left\{\beta_{1} x_{3}\right\} \\
& L_{3}=\sup _{t \in\left[t_{0}, T\right]}\left\{\alpha_{3} x_{1}+\eta_{1} x_{4}+k_{3}+\frac{\xi_{3} \sigma_{3}}{\lambda_{3}+x_{5}}\right\} \\
& m_{3}=\inf _{r \in\left[t_{0}, T\right]}\left\{\beta_{2} x_{2} x_{3}+\beta_{3} x_{3}\right\} \\
& L_{4}=\inf _{t \in\left[t_{0}, T\right]}\left\{K_{2} x_{2}+\eta_{2} x_{3}+k_{4}\right\} \\
& L_{5}=\inf _{t \in\left[t_{0}, T\right]}\left\{\frac{\sigma_{0}}{\lambda_{0}+x_{5}}+\frac{\sigma_{2} x_{2}}{\lambda_{2}+x_{5}}+\frac{\sigma_{3} x_{3}}{\lambda_{3}+x_{5}}\right\}
\end{aligned}
$$

Then the following differential inequalities are obtained:

$$
\left\{\begin{array}{l}
\dot{x}_{1} \geq S_{1}+m_{1}-L_{1} x_{1}-e_{10} \\
\dot{x}_{2} \geq S_{2}+m_{2}-L_{2} x_{2}-U_{1}-e_{20} \\
\dot{x}_{3} \geq S_{3}+m_{3}-L_{3} x_{3}-e_{30} \\
\dot{x}_{4} \geq S_{4}+m_{4}-L_{4} x_{4}-e_{40} \\
\dot{x}_{5} \geq D-L_{5} x_{5} \\
x_{1}\left(t_{0}\right)=x_{10} \text { where } i=\{1,2,3,4,5\}
\end{array}\right.
$$

Therefore, the following inequalities are obtained:

$$
\left\{\begin{array}{l}
x_{1} \geq \frac{S_{1}+m_{1}-e_{10}}{L_{1}}+d_{1} e^{-L_{1} t} \\
x_{2} \geq \frac{S_{2}+m_{2}-U_{1}-e_{20}}{L_{2}}+d_{2} e^{-L_{2} t} \\
x_{3} \geq \frac{S_{3}+m_{3}-e_{30}}{L_{3}}+d_{3} e^{-L_{3} t} \\
x_{4} \geq \frac{S_{4}+m_{4}-e_{40}}{L_{4}}+d_{4} e^{-L_{4} t} \\
x_{5} \geq \frac{D}{L_{5}}+d_{5} e^{-L_{5} t}
\end{array}\right.
$$

The system will exhibit persistence if

$$
\left\{\begin{array}{l}
\lim \text { inf } x_{1} \geq \frac{S_{1}+m_{1}-e_{10}}{L_{1}}>0 \\
\lim \inf x_{2} \geq \frac{S_{2}+m_{2}-U_{1}-e_{20}}{L_{2}}>0 \\
\lim \inf x_{3} \geq \frac{S_{3}+m_{3}-e_{30}}{L_{3}}>0 \\
\lim \inf x_{4} \geq \frac{S_{4}+m_{4}-e_{40}}{L_{4}}>0 \\
\lim \inf x_{5} \geq \frac{D}{L_{5}}>0
\end{array}\right.
$$

\section{Necessary Criteria for cure of AIDS during HAART}

One of the desired physiological steady states during HAART therapy is $\mathrm{E}=\left[\hat{x}_{1}, 0,0,0, \hat{x}_{5}\right]$. In this configuration, the HIV-1 infected $\mathrm{T}_{4}$ helper cells $\left(x_{2}\right)$, and HIV-1 virions $\left(x_{3}\right)$, and HIV-1 specific cytotoxic $\mathrm{T}_{8}$ cells $\left(x_{4}\right)$ are annihilated by the HAART therapy.

The necessary conditions for the cure of AIDS using constant continuous transdermal infusion HAART therapy include:

$$
\left\{\begin{array}{l}
S_{1}+a_{1} \hat{x}_{1}^{2} e^{-b_{1} \hat{x}_{4}}-k_{1} \hat{x}_{1}-e_{10}=0 \\
S_{2}-e_{20}=0 \\
S_{3}-e_{30}=0 \\
S_{4}+a_{4} \hat{x}_{1} \hat{x}_{4} e^{-b_{4} \hat{x}_{4}}-k_{4} \hat{x}_{4}-e_{40}=0 \\
D-\frac{\sigma_{0} \hat{x}_{5}}{\lambda_{0}+\hat{x}_{5}}=0
\end{array}\right.
$$


The sufficient conditions for the cure of AIDS can be obtained using a Liapunov functional, to guarantee that $\mathrm{E}=\left[\hat{x}_{1}, 0,0,0, \hat{x}_{5}\right]$ is globally asymptotically stable. This will be done in a future publication.

\section{SIMULATION RESULTS AND DISCUSSION}

The computer simulations are performed using hypothetical AIDS patients' configuration $P_{1}$ and $P_{2}$, as exhibited in Table I and Table II. It should be stressed that the data values are estimates and some are from the literature values listed in $[4,5,11,12]$. Realistic parameters can only be obtained from actual AIDS patients under clinical conditions. Several investigative computer simulations are performed depicting the scenarios of viral persistence and viral annihilation. Two samples of the simulations are exhibited in Figure 1 for constant continuous transdermal infusion and Figure 2 for periodic transdermal infusion.

TABLE I. CONSTANT CONTINUOUS TRANSDERMAL INFUSION PARAMETRIC CONFIGURATION $P_{1}$

\begin{tabular}{|c|c|c|c|c|}
\hline $\begin{array}{l}S_{1}=400 / \text { day } / \mu l \\
a_{1}=0.03 / \text { day } / \text { cell } / \mu l \\
b_{1}=0.1 / \text { cell } / \mu l \\
\alpha_{1}=0.5 / \text { day } / \text { virion } / \mu l \\
k_{1}=0.0005 / \text { day } / \mu l \\
q_{1}=0.00045 / \text { day } / \mu l / \text { cell } \\
\mathrm{e}_{10}=1.9 \text { cells } / \text { day } / \mu l \\
x_{10}=200 \text { cells } / \mu l\end{array}$ & $\begin{array}{l}S_{2}=800 / \text { day } / \mu l \\
a_{2}=0.03 / \text { day } / \mathrm{cell} / \mu l \\
b_{2}=0.004 / \mathrm{cell} / \mu l \\
a_{2}=0.5 / \text { day } / \text { virion } / \mu l \\
k_{2}=0.005 / \text { day } / \mu l \\
q_{2}=0.00001 / \text { day } / \mu l / \text { cell } \\
\beta_{1}=1.5 \text { virons } / \mathrm{CD}^{+} / \text {day } \\
K_{1}=0.0001 / \text { day } / \mu l \\
e_{20}=0.0005 \mathrm{cells} / \text { day } / \mu l \\
x_{20}=400 \mathrm{cells} / \mu l\end{array}$ & $\begin{array}{l}S_{3}=1000 / \text { day } / \mu l \\
\beta_{2}=0.025 \text { virons } / \mathrm{CD}^{+} / \text {day } / \mu l \\
\beta_{3}=1.5 \text { virons } / \mathrm{CD}^{+} / \text {day } \\
\alpha_{3}=0.027 / \text { day } / \text { virion } / \mu l \\
k_{3}=0.0001 / \text { day } \\
e_{30}=0.0001 / \text { day } \\
\eta_{1}=0.25 \\
\xi_{2}=0.85 \\
\xi_{3}=0.001 \\
x_{30}=500 \text { cells } / \mu l\end{array}$ & $\begin{array}{l}S_{4}=0.272 / \mathrm{day} / \mu l \\
a_{4}=0.03 / \mathrm{day} / \mathrm{cell} / \mu l \\
b_{4}=0.01 / \mathrm{cell} / \mu l \\
K_{2}=0.0024 / \mathrm{day} / \mu l \\
k_{4}=0.008 / \text { day } / \mu l \\
e_{40}=0.0002 \mathrm{cells} / \mathrm{day} / \mu l \\
\eta_{2}=0.45 \\
x_{40}=800 \mathrm{cells} / \mu l\end{array}$ & $\begin{array}{l}\mathrm{D}=1000 \text { units } \\
\sigma_{0}=50 \mathrm{mg} / \mathrm{day} \\
\sigma_{2}=50.98 \mathrm{mg} / \text { day } \\
\sigma_{3}=10 \mathrm{mg} / \text { day } \\
\lambda_{0}=5 \mathrm{mg} / \mathrm{L} \\
\lambda_{2}=5.5 \mathrm{mg} / \mathrm{L} \\
\lambda_{3}=2.5 \mathrm{mg} / \mathrm{L} \\
x_{50}=1000 \mathrm{cells} / \mu \mathrm{l}\end{array}$ \\
\hline
\end{tabular}
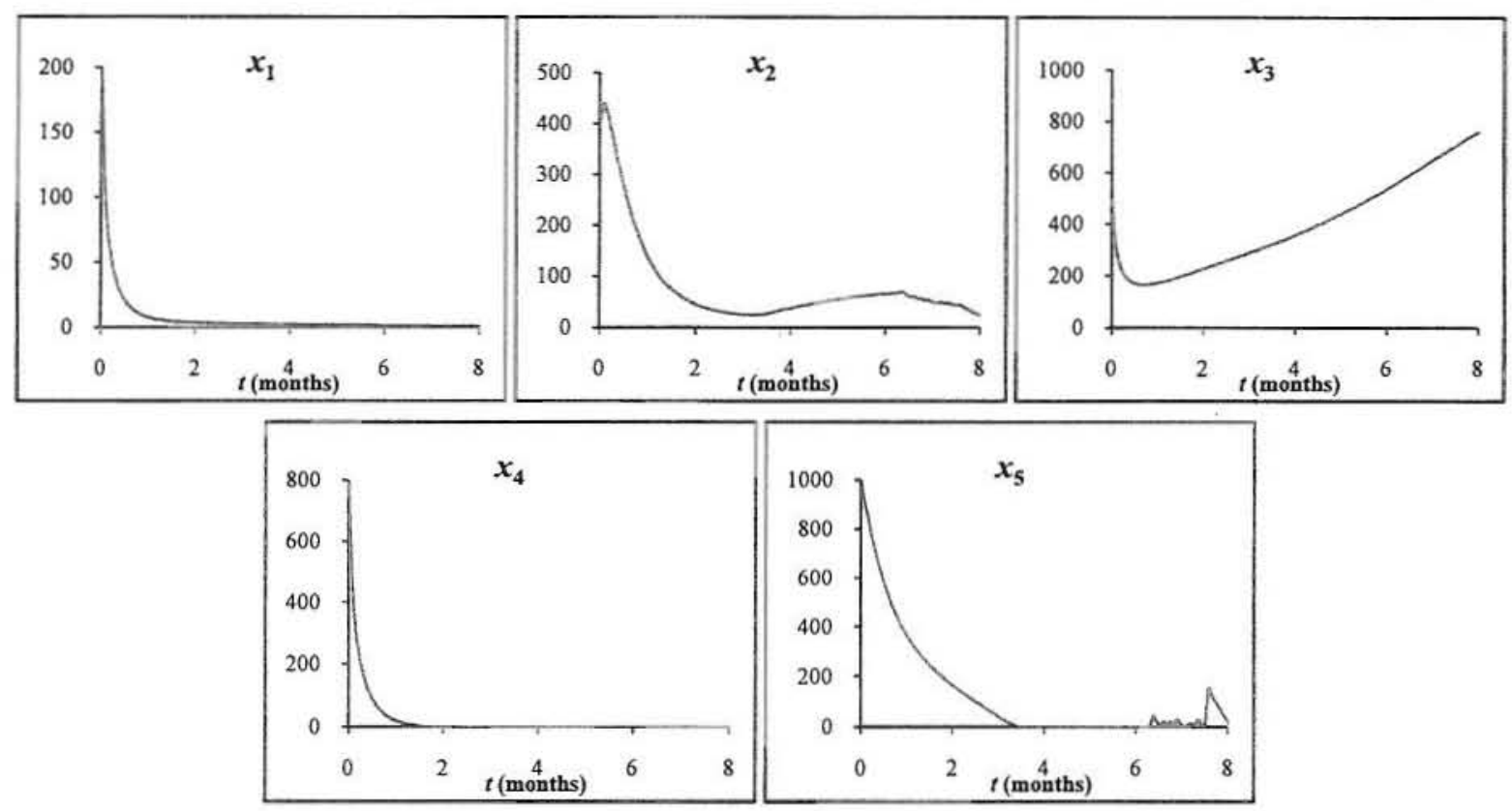

Figure 1. Simulation results using parametric configuration $P_{1}$

TABLE II. PERIOdIC TRANSDERMAL INFUSION PARAMETRIC CONFIGURATION $P_{2}$

\begin{tabular}{|c|c|c|c|c|}
\hline $\begin{array}{l}S_{1}=400 / \text { day } / \mu l \\
a_{1}=0.03 / \text { day } / \mathrm{cell} / \mu l \\
b_{1}=0.01 / \mathrm{cell} / \mu l \\
\alpha_{1}=0.5 / \text { day } / \mathrm{virion} / \mu l \\
k_{1}=0.0005 / \text { day } / \mu l \\
q_{1}=0.00045 / \text { day } / \mu l / \mathrm{cell} \\
\mathrm{e}_{10}=0.0025 \mathrm{cells} / \mathrm{day} / \mu l \\
x_{10}=200 \mathrm{cells} / \mu l\end{array}$ & $\begin{array}{l}S_{2}=800 / \text { day } / \mu l \\
a_{2}=0.03 / \text { day } / \text { cell } / \mu l \\
b_{2}=0.004 / \text { cell } / \mu l \\
a_{2}=0.5 / \text { day } / \text { virion } / \mu l \\
k_{2}=0.005 / \text { day } / \mu l \\
q_{2}=0.00001 / \text { day } / \mu l / \text { cell } \\
\beta_{1}=1.5 \mathrm{virons} / \mathrm{CD} 4^{*} / \text { day } \\
K_{1}=0.0001 / \text { day } / \mu l \\
e_{20}=0.0005 \mathrm{cells} / \text { day } / \mu l \\
x_{20}=400 \mathrm{cells} / \mu l\end{array}$ & $\begin{array}{l}S_{3}=10 / \text { day } / \mu l \\
\beta_{2}=0.025 \text { virons } / \mathrm{CD}^{*} / \text { day } / \mu l \\
\beta_{3}=1.5 \text { virons } / \mathrm{CD}^{*} / \text { day } \\
\alpha_{3}=0.027 / \text { day } / \text { virion } / \mu l \\
k_{3}=0.0001 / \text { day } \\
e_{30}=0.0001 / \text { day } \\
\eta_{1}=0.25 \\
\xi_{2}=0.85 \\
\xi_{3}=0.001 \\
x_{30}=500 \text { cells } / \mu l\end{array}$ & $\begin{array}{l}S_{4}=10 / \mathrm{day} / \mu l \\
a_{4}=0.75 / \mathrm{day} / \mathrm{cell} / \mu l \\
b_{4}=0.01 / \mathrm{cell} / \mu l \\
K_{2}=0.00024 / \mathrm{day} / \mu l \\
k_{4}=0.08 / \mathrm{day} / \mu l \\
e_{40}=0.0002 \mathrm{cells} / \mathrm{day} / \mu l \\
\eta_{2}=0.45 \\
x_{40}=750 \mathrm{cells} / \mu l\end{array}$ & $\begin{array}{l}\mathrm{D}=1000 \text { units } \\
\sigma_{0}=10 \mathrm{mg} / \text { day } \\
\sigma_{2}=100 \mathrm{mg} / \text { day } \\
\sigma_{3}=10 \mathrm{mg} / \text { day } \\
\lambda_{0}=5 \mathrm{mg} / \mathrm{L} \\
\lambda_{2}=10 \mathrm{mg} / \mathrm{L} \\
\lambda_{3}=2.5 \mathrm{mg} / \mathrm{L} \\
x_{50}=1500 \mathrm{cells} / \mu \mathrm{l} \\
n=4\end{array}$ \\
\hline
\end{tabular}



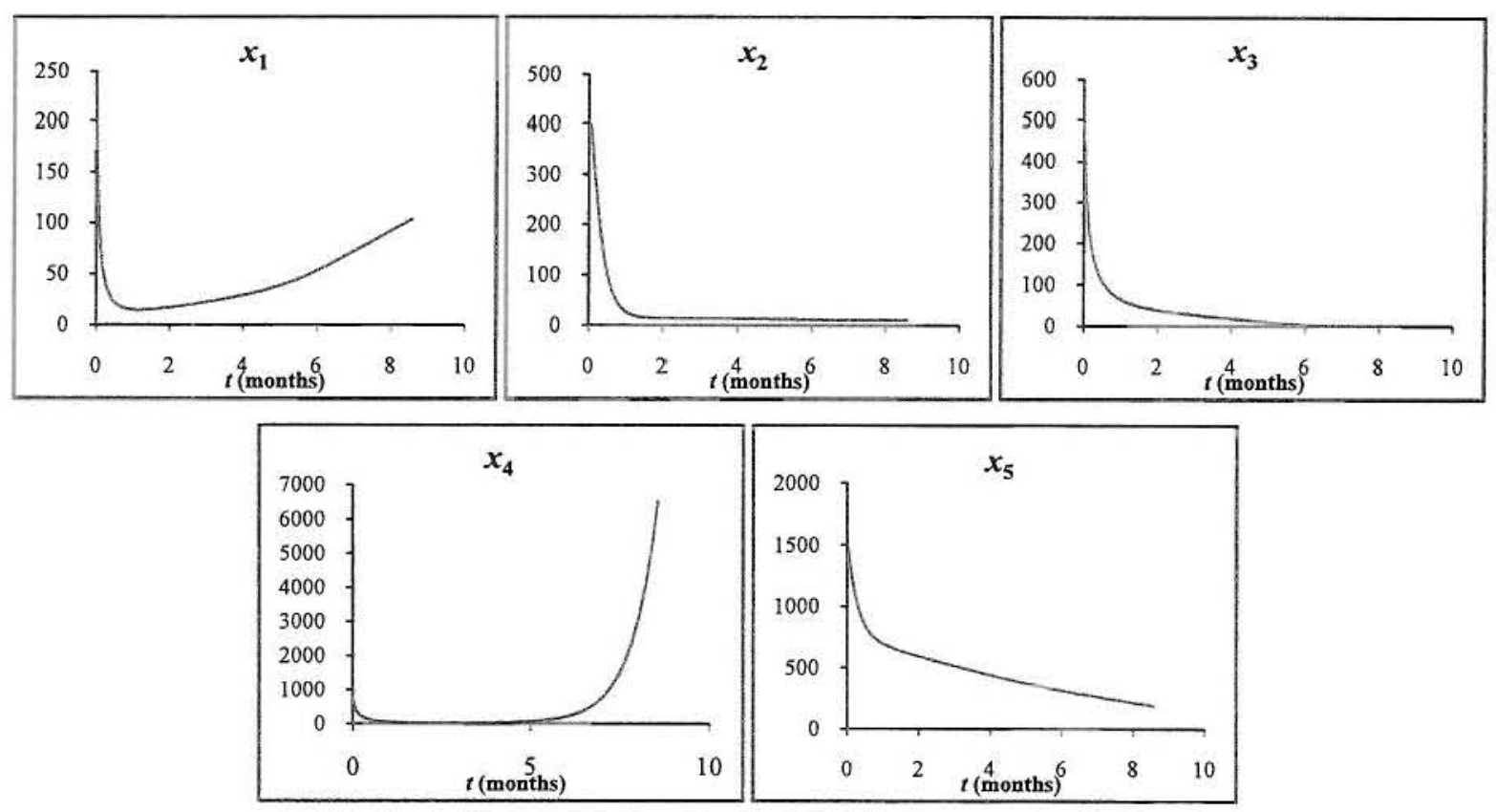

Figure 2. Simulation results using parametric configuration $P_{2}$

It is observed that, in principle, AIDS can be cured. In particular, using parametric configuration $P_{1}$ for constant continuous transdermal infusion, the HAART therapy was unsuccessful because the HIV-1 virions increased dramatically during the therapy, whereas the $\mathrm{CD} 4{ }^{+}$helper $\mathrm{T}$ cells were eliminated. In Figure 2 , using periodic transdermal infusion with parametric configuration $P_{2}$, it is observed that the HAART therapy was successful because the HIV-1 virions were annihilated, whereas the $\mathrm{CD}^{+}$helper T cells and the $\mathrm{CD}^{+} \mathrm{HIV}-1$ specific cytotoxic $\mathrm{T}$ cells repopulated.

It should be mentioned that there are other simulation scenarios in which the constant continuous transdermal infusion were successful and the periodic transdermal infusion were unsuccessful. Those scenarios will be presented in a future paper.

\section{SUMMARIZING REMARKS}

In this paper, a clinically plausible mathematical model for HAART therapy is presented which incorporates the patho-physiological dynamics of HIV-1 virions. The novel transdermal route of drug delivery which minimizes drug toxicity is utilized. The simulations of the model show that for some given AIDS patients' parametric configurations, it is possible to cure AIDS. The necessary mathematical criteria for these scenarios have been presented in the paper. The next step in the research towards the cure for AIDS is to investigate whether these results can be achieved in vivo as well as in the human AIDS patients.

\section{REFERENCES}

[1] B. M. Adams, et al., "HIV dynamics: Modeling, data analysis, and optimal treatment protocols". Journal of Computational and Applied Mathematics, vol. 184, pp. 10-49, 2005

[2] MAL. Caetano and T. Yoneyama, "Short and long period optimization of drug doses in the treatment of AIDS", Anais da Academia Brasileira de Ciências, Vol. 74(003), pp. 379-392, 2002

[3] A. Carr, "Toxicity of antiretroviral therapy and implications for drug development", Nature Reviews Drug Discovery 2, pp. 624-634, Aug. 2003

[4] D. E. Kirschner, and G. F. Webb, "A mathematical model of combined drug therapy of HIV-1 infection", Journal of Theoretical Medicine, vol. 1, pp. 25-34, 1997

[5] D. E. Kirschner, and G. F. Webb, "Understanding drug resistance for infection", Bulletin of Math Biology, vol. 59, pp. 763-785, 1997

[6] S. Jain, A. K. Tiwary, N. K. Jain, "Transdermal delivery of an anti-HIV agent using elastic liposomes: mechanism of action", Current Drug Delivery, vol. 3(2), pp. 157-166, 2006

[7] M. Joly, J. M. Pinto, "Role of mathematical modeling on the optimal control of HIV-1 pathogenesis", AIChE J., vol. 52, pp. 856-884, 2006

[8] H. R. Joshi, "Optimal control of an HIV immunology model", Optim. Contr. Appl. Math., vol. 23, pp. 199-213, 2002

[9] S. Linsay, et al., "Short-term Discontinuation of HAART regimens", AIDS Research and Human Retroviruses, vol. 24, pp. 1347-1355, 2008

[10] R. Moh, C. Danel et at., "Haematological changes in adults receiving a zidovudine HAART regimen in combination with cotrimazole in Côte d'Ivoire", Antiviral Therapy, vol. 10, pp. 615-624, 2005

[11] F. Nani and M. Jin, "Mathematical modeling and simulation of latency phase HIV-1 dynamics", Int'1 Conf. Bioinformatics and Computational Biology (BIOCOMP'10), Vol. II, pp. 428-434, July 2010

[12] A. S. Perelson et al., "Decay characteristics of HIV-1 infected compartments during combination therapy", Nature, vol. 387, pp. 188-191, 1997

[13] B. Song, J. Lou, Q. Wen, "Modeling two different therapy strategies for drug T-20 on HIV-1 patients", Appl. Math. Mech. Engl. Ed., vol. 32(4), pp. $419-436,2011$

[14] R. F. Stengel, "Mutation and control of the human immunodeficiency virus", Mathematical Biosciences, vol. 231, pp. 93-102, 2008

[15] P. Ye, A. P. Kourtis, and D. E. Kirschner, "Reconstitution of thymic function in HIV-1 patients treated with highly active antiretroviral therapy", Clinical Immunology, vol. 106, pp. 95-105, 2003. 
